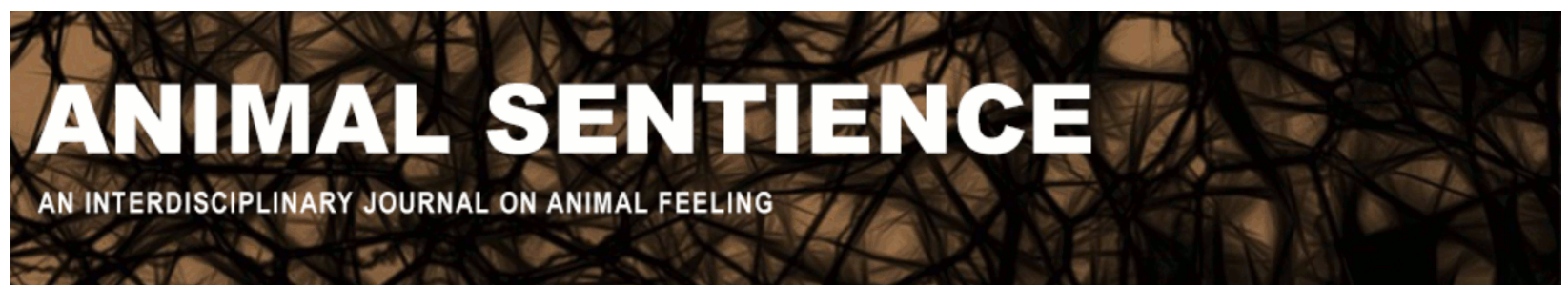

Massiot, Elodie (2020) Challenging our conception of wildness. Animal Sentience 28(19)

DOI: $10.51291 / 2377-7478.1581$

Date of submission: $2020-05-20$

Date of acceptance: 2020-05-28

(c)

This article has appeared in the journal Animal

Sentience, a peer-reviewed journal on animal

cognition and feeling. It has been made open access,

free for all, by WellBeing International and deposited

in the WBI Studies Repository. For more information,

please contact

wbisr-info@wellbeingintl.org.

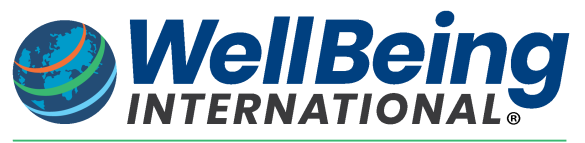

SOLUTIONS FOR PEOPLE, ANIMALS AND ENVIRONMENT 


\title{
Challenging our conception of wildness
}

Commentary on Baker \& Winkler on Elephant Rewilding

\author{
Elodie Massiot \\ ONG Mahout Elephant Foundation
}

\begin{abstract}
Baker \& Winkler (2020) point out the entanglement among free-living elephants, captive elephants, and humans in the elephant tourism industry. Where all living beings captive and free-living - are more or less affected by human presence or activity, the binary notion of wild and captive, and in situ and ex situ conservation, becomes inadequate. B\&W challenge our concept of wildness - and hence of rewilding - and our level of intervention in this wildness of which we are a component.
\end{abstract}

Elodie Massiot holds a Master's degree in Ecophysiology and Ethology from Strasbourg University (France). She is a Research Fellow with Mahouts Elephants Foundation, monitoring elephant behavior. She also consults with World Animal Protection to assess the welfare of elephants in their elephant-friendly transitioning program. Website

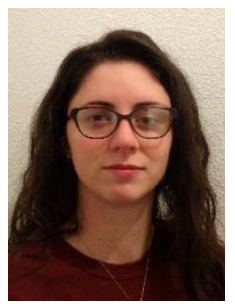

Baker \& Winkler (2020) (B\&W) make a good case for according equal attention to free and captive Asian elephants in addressing the problem of entanglement in the elephant tourism industry. Their concept of rewilding erases the borders between free-living elephants, captive elephants, and the humans that live with and among them. It also challenges our concept of wildness and the viability of conventional conservation and welfare. This commentary will address notions of wildness in various contexts and their implications for the notion of rewilding.

\section{Human interventions and free-living wild animals}

B\&W highlight that even free-living elephant populations are affected by human presence and activity. Conflicts with humans alter the pattern and timing of the activities of free-living elephants and even the genetics of some populations (e.g., Graham et al., 2009; Archie and Chiyo, 2012; Srinivasaiah et al., 2012).

To counteract this threat, conservationists focus their in situ conservation efforts on highly managed elephant populations living in protected areas. They act directly on these populations, monitoring their movement and behavior and restoring or even modifying their habitat, for example, by creating water sources to limit movement patterns that cause conflicts with villagers (Parr et al., 2008; van de Water and Matteson, 2018). Even wellintentioned conservation interventions can modify behavior. Managed populations nevertheless continue to be considered wild according to the International Union for Conservation of Nature's Red List, because the purpose of such measures to sustain the population in the long term (Child et al., 2019).

As the remaining areas free of human intervention shrink, there is human impact on both threatened and protected free-living elephant populations. When their ecological and evolutionary functions continue, these populations are still considered part of wildness (Child et al., 2019; Snijders, 2020). Defining wildness on the basis of total absence of human 
intervention, as some commentaries suggest (e.g., Kopnina, 2020; Blumstein and Lynch, 2020), no longer reflects the reality of the Antropocene era.

\section{Human interventions and captive wild animals}

In captivity, wildness refers more to the genetic variability and sustainability of the population (Braverman, 2014). Zoo breeding programs are now considered ex situ conservation, creating a sustainable captive preserve for endangered or extinct species (Braverman, 2014). Moreover, studies on captive environments focus mostly on improving animal welfare. Their main aim is to bring the behavioral repertoire of the captive individuals more in line with the 'natural behavior' of their free-living counterparts.

Some conservationists emphasize the need to consider the entire species, under all management conditions, and argue for involving all the parties - conservationists, politicians, citizens - through the One Plan approach (Braverman, 2014). Both captive individuals in ex situ conservation programs and free-living individuals in in situ programs are considered important for the protection of the entire species. The distinction between in situ and ex situ conservation, and captive and wild populations, has thus become blurred. Should captive populations involved in the efforts to conserve the species be considered part of wildness? In assessing both individual welfare and species conservation, B\&W's rewilding project would help erase the disparities between in situ and ex situ conservation, captive and free-living populations.

\section{Human interventions and the rewilding process}

The concept of rewilding is applicable at different scales - from individuals to territories - all intended to provide greater autonomy (Prior and Ward, 2016). At the individual level, autonomy can be defined as the freedom to act on the basis of needs or desires (Thomas, 2016). Individual rewilding, as B\&W propose, aims to gradually enable individual elephants to act autonomously within the space we allot them (Prior and Ward, 2016). For example, World Animal Protection (WAP) helps develop tourism programs that allow no direct interaction with tourists. It reduces the elephant management needed to permit safe human proximity, allowing elephants greater personal choice.

For Cookson (2011), 'wildness depends on the quality of interaction from and among its components'. Rehabilitating individual elephants increases this interaction with the environment and social partners. In venues helped by WAP, elephants are free to explore their environment, forage in forest areas, and interact socially without human control. Contrary to the belief of Suter (2020), this rehabilitation goes much further than just welfare improvement measures.

Recent rewilding studies include human components (Prior and Ward, 2016). As Paukatet (2020) and Lainé (2020) point out, taking local culture into consideration is essential for effective and sustainable conservation (Lainé, 2018; DeSilvey and Bartolini, 2019). Kopnina (2020) suggests that the traditional mahout-elephant relationship, or the recognition of humans as part of nature, is not sufficient to warrant considering human interventions as beneficial to elephant rewilding. But a notion of rewilding dissociated from human influences seems disconnected from the reality of the Anthropocene era. It reflects a concept of wildness based on the Western cultural dichotomy between humans and wildness; in Karen culture, there is a close synergy with wildness (Cookson, 2011). Humans, like any other species, influence and interact with other species. This inter-species interaction should not be considered negative in and of itself. 
Of the elephants living in human-dominated landscapes, in highly managed national parks, or alongside indigenous mahouts: which of them should be considered wild or captive? As the distinction between wild and captive, or in situ and ex situ conservation, turns out to be a matter of degree, the wildness of individuals depends on the nature of their interaction with the other components of wildness (Cookson, 2011). We humans need to recognize that we are components of wildness too.

\section{References}

Archie, E. A., and Chiyo, P. I. (2012). Elephant behaviour and conservation: Social relationships, the effects of poaching, and genetic tools for management. Molecular Ecology, 21(3): 765-778.

Baker, L., and Winkler, R. (2020). Asian elephant rescue, rehabilitation and rewilding. Animal Sentience 28(1).

Blumstein, D. T., and Lynch, K. E. (2020). Innovative, yes: But is it rewilding? Animal Sentience 28(8).

Braverman, I. (2014). Captive for life: Conserving extinct in the wild species through ex situ breeding. In The Ethics of Captivity (p. 31), L. Gruen, ed. Oxford University Press.

Child, M. F., Selier, S. A. J., Radloff, F. G. T., Taylor, W. A., Hoffmann, M., Nel, L., Power, R. J., Birss, C., Okes, N. C., Peel, M. J., Mallon, D., and Davies-Mostert, H. (2019). A framework to measure the wildness of managed large vertebrate populations. Conservation Biology, 33(5): 1106-1119.

Cookson, L. J. (2011). A definition for wildness. Ecopsychology, 3(3): 187-193.

DeSilvey, C., and Bartolini, N. (2019). Where horses run free? Autonomy, temporality and rewilding in the Côa Valley, Portugal. Transactions of the Institute of British Geographers, 44(1): 94-109.

Graham, M. D., Douglas-Hamilton, I., Adams, W. M., and Lee, P. C. (2009). The movement of African elephants in a human-dominated land-use mosaic. Animal Conservation, 12(5): 445-455.

Jørgensen, D. (2015). Rethinking rewilding. Geoforum, 65: 482-488.

Kopnina, H. (2020). Of elephants and men. Animal Sentience 28(2).

Lainé, N. (2018). Asian elephant conservation: Too elephantocentric? Towards a biocultural approach of conservation. Asian Bioethics Review, 10(4): 279-293.

Lainé, N. (2020). Anthropology and conservation. Animal Sentience 28(5).

Parr, J. W. K., Jitvijak, S., Saranet, S., and Buathong, S. (2008). Exploratory co-management interventions in Kuiburi National Park, Central Thailand, including human-elephant conflict mitigation. International Journal of Environment and Sustainable Development, 7(3): 293.

Pauketat J. VT. (2020). A psychological perspective on elephant rewilding. Animal Sentience 28(4).

Powell, D.M., \& Vitale, C. (2016). Behavioral changes in female Asian elephants when given access to an outdoor yard overnight: Indoor-Outdoor Elephant Nocturnal Behavior. Zoo Biology, 35: 298-303.

Prior, J., and Ward, K. J. (2016). Rethinking rewilding: A response to Jørgensen. Geoforum, 69: 132-135. 
Snijders, L. (2020). Ecological and evolutionary dynamics of elephant rewilding. Animal Sentience 28(6).

Srinivasaiah, N. M., Anand, V. D., Vaidyanathan, S., and Sinha, A. (2012). Usual populations, unusual individuals: Insights into the behavior and management of Asian Elephants in fragmented landscapes. PLOS ONE, 7(8): e42571.

Suter, I. (2020). Rewilding or reviewing: Conservation and the elephant-based tourism industry. Animal Sentience 28(3).

Thitaram, C., Dejchaisri, S., Somgird, C., Angkawanish, T., Brown, J., Phumphuay, R., Chomdech, S., and Kangwanpong, D. (2015). Social group formation and genetic relatedness in reintroduced Asian elephants (Elephas maximus) in Thailand. Applied Animal Behaviour Science, 172: 52-57.

Thomas, N. (2016). Autonomy and animals. In Animal Ethics and the Autonomous Animal Self. Palgrave Macmillan, London

van de Water, A., and Matteson, K. (2018). Human-elephant conflict in western Thailand: Socio-economic drivers and potential mitigation strategies. PLOS ONE, 13(6): e0194736. 


\section{Call for Papers}

Special Issue of the Lournal of Consciousness Studies

Plant Sentience: Theoretical and Empirical Issues

Guest Editors: Vicente Raja (Rotman Institute of Philosophy, Western University)

Miguel Segundo-Ortin (School of Liberal Arts, University of Wollongong)

In this special issue, we address the issue of plant sentience/consciousness from different disciplines that combine both theoretical and empirical perspectives. Some of the questions to be addressed in the special issue include the following:

- Plants exhibit interesting behaviors; does this entail that they are conscious to some extent?

- What are the requirements for a living organism to be conscious? Do plants meet these requirements?

- What does the possibility of plant sentience/consciousness entail for the study of the evolution of consciousness?

- Is it just a categorical mistake to attribute consciousness to plants?

- Can we talk about different levels or degrees of consciousness?

\section{How to submit?}

\section{Deadline: June $\mathbf{1}^{\text {st }}, \mathbf{2 0 2 0}$}

Please submit your papers (max. 9000 words including footnotes, references, abstract, etc.) to vgalian@uwo.ca with subject "Paper Special Issue JCS".

For more information, including bibliography and more detailed descriptions of the topics and questions to be addressed in the papers submitted to the special issue, please contact the guest editors at vgalian@uwo.ca (Vicente) or mso693@uowmail.edu.au (Miguel). 


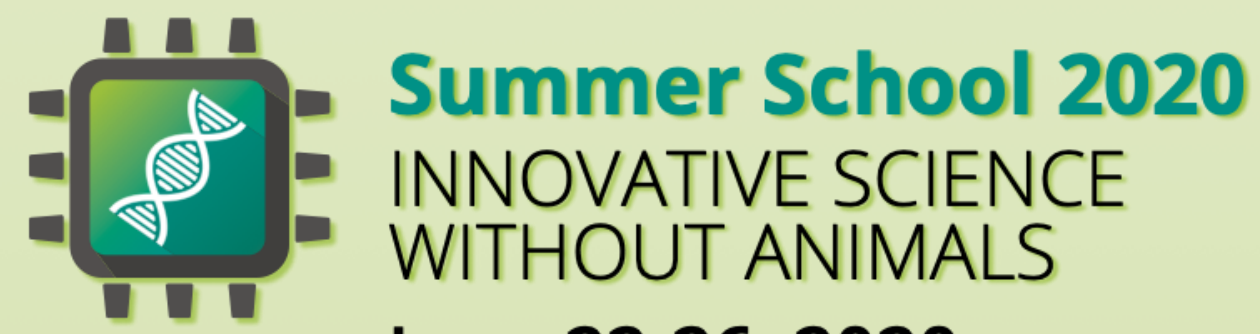

\section{June 22-26, 2020 \\ Online Virtual Conference}

\section{Calling all students and early-career researchers!}

Join us for a FREE conference on innovative approaches in toxicology and biomedical sciences!

\section{This event features:}

- Lecture sessions about modern alternatives to the use of animals in toxicology and biomedical sciences

Virtual laboratory tours

E-poster presentations

- Virtual engagement with speakers and attendees

Deadline to apply for the full program is June 10 .

Registration for individual lectures is available.

For more information visit InnovativeScience2020.org

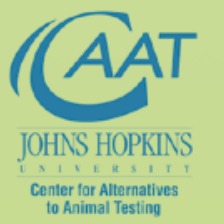

Physicians

for Responsible Medicine

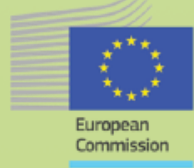

